\title{
SCIENTIFIC REPORTS

\section{OPEN Performance of novel MgS doped cellulose nanofibres for Cd(II) removal from industrial effluent - mechanism and optimization}

Received: 12 June 2019

Accepted: 19 August 2019

Published online: 02 September 2019

\begin{abstract}
Nalini Sankararamakrishnan ${ }^{1}$, Rishabh Singh $^{1,2}$ \& lla Srivastava ${ }^{1}$
Green environment friendly and novel nano MgS decorated cellulose nanofibres (MgS@CNF) were prepared, characterized and evaluated towards the removal of heavy metal namely, cadmium from aqueous solutions. Cellulose nanofibres acted as a template for effective dispersion of $\mathrm{MgS}$ nanoparticles and also aid in the complexation of cadmium ions. In depth X-ray photoelectron spectroscopy (XPS), X-ray diffraction (XRD) and Fourier transform infra red spectroscopy (FTIR) studies revealed that doped $\mathrm{MgS}$ on mild acidification yields insitu production of $\mathrm{H}_{2} \mathrm{~S}$ which effectively complexes cadmium ion to form cadmium sulfide. The reaction followed pseudo first order kinetics with regression coefficient in the order of 0.98 . A very high Langmuir adsorption capacity in the order of $333.33 \mathrm{mg} / \mathrm{g}$ was obtained for MgS@CNF. Finally, MgS@CNF was applied towards the removal of cadmium from organic and TDS rich tannery waste water. MgS@CNF was effective in bringing down the concentration from ppm to ppb levels.
\end{abstract}

\begin{abstract}
Heavy metal pollution by industrial wastewater is one of the indispensable environmental challenges worldwide. Among various heavy metals, non-biodegradability and bioaccumulation makes Cadmium (Cd) as one of the most toxic heavy metals ${ }^{1}$. Cadmium primarily finds use in plastics and steel production and it has been listed as Group-B1 and category-I carcinogen by the US EPA and International Agency for Research on Cancer respectively ${ }^{2}$. Mainly Cd accumulates in bones, pancreas, livers and kidneys, and, which causes various ailments like nephritis, neuralgia, hypertension, secretion disorder and anemia ${ }^{3}$. Various methods have been reported for removal including chemical precipitation, reverse osmosis, adsorption, and ion-exchange ${ }^{4}$. Among these methods, removal of heavy metal contamination by adsorption process is considered as economic, reliable, and effective method ${ }^{5,6}$. Various adsorbents like activated carbon ${ }^{7}$, zeolites ${ }^{8}$, nanozerovalent iron ${ }^{9,10}$, carbon nano tubes ${ }^{11,12}$, graphene $e^{13}$, functionalized chitosan ${ }^{14,15}$, low cost agricultural wastes ${ }^{16,17}$ have been found useful for its removal. It is to be noted among these, adsorbents modified with sulfur containing ligands exhibited excellent adsorption capacity owing to soft-soft interaction effective complexation of Cd and sulphur ligands ${ }^{15,18,19}$. Further it was also observed that nanocomposites with increased surface area provided efficient metal ion binding ${ }^{20,21}$. Thus in this work green biodegradable cellulose nanofibers were extracted from low cost agricultural waste sugarcane bagasse and nano MgS were effectively doped on this nanofiber and evaluated for its capacity towards cadmium. This is the first time we have reported a novel $\mathrm{MgS}$ doped bio-nanocomposite. Cellulose nanofiber provides a template for effective dispersion of $\mathrm{MgS}$ and also helps in preventing the agglomeration of the nano MgS. Characterization with various analytical techniques, optimization, mechanism of interaction and its application towards cadmium removal from tannery waste water are detailed in the following sections.
\end{abstract}

\section{Results and Discussion}

Characterization of MgS@CNF and mechanism of interaction. The scanning electroscopy images of MgS@CNF and Cd loaded MgS@CNF are shown in Fig. 1a,b respectively. It is evident MgS is uniformly loaded on nanofibers and adsorption of $\mathrm{Cd}$ on the surface of the fibers is also clear. Further EDX spectra revealed the presence of Mg, S and Cd on Cd loaded MgS@CNF (Fig. 1c). The FTIR spectra MgS@CNF are shown in Fig. 2a. Broad band around $3700 \mathrm{~cm}^{-1}$ in both MgS@CNF and Cd-MgS@CNF could be attributed to -OH stretching

${ }^{1}$ Centre for Environmental Science and Engineering, Indian Institute of Technology Kanpur, Kanpur, U. P., 208016, India. ${ }^{2}$ Department of Environmental Science and Technology, Banaras Hindu University, Varanasi, U.P., 221005, India. Correspondence and requests for materials should be addressed to N.S. (email: nalini@iitk.ac.in) 

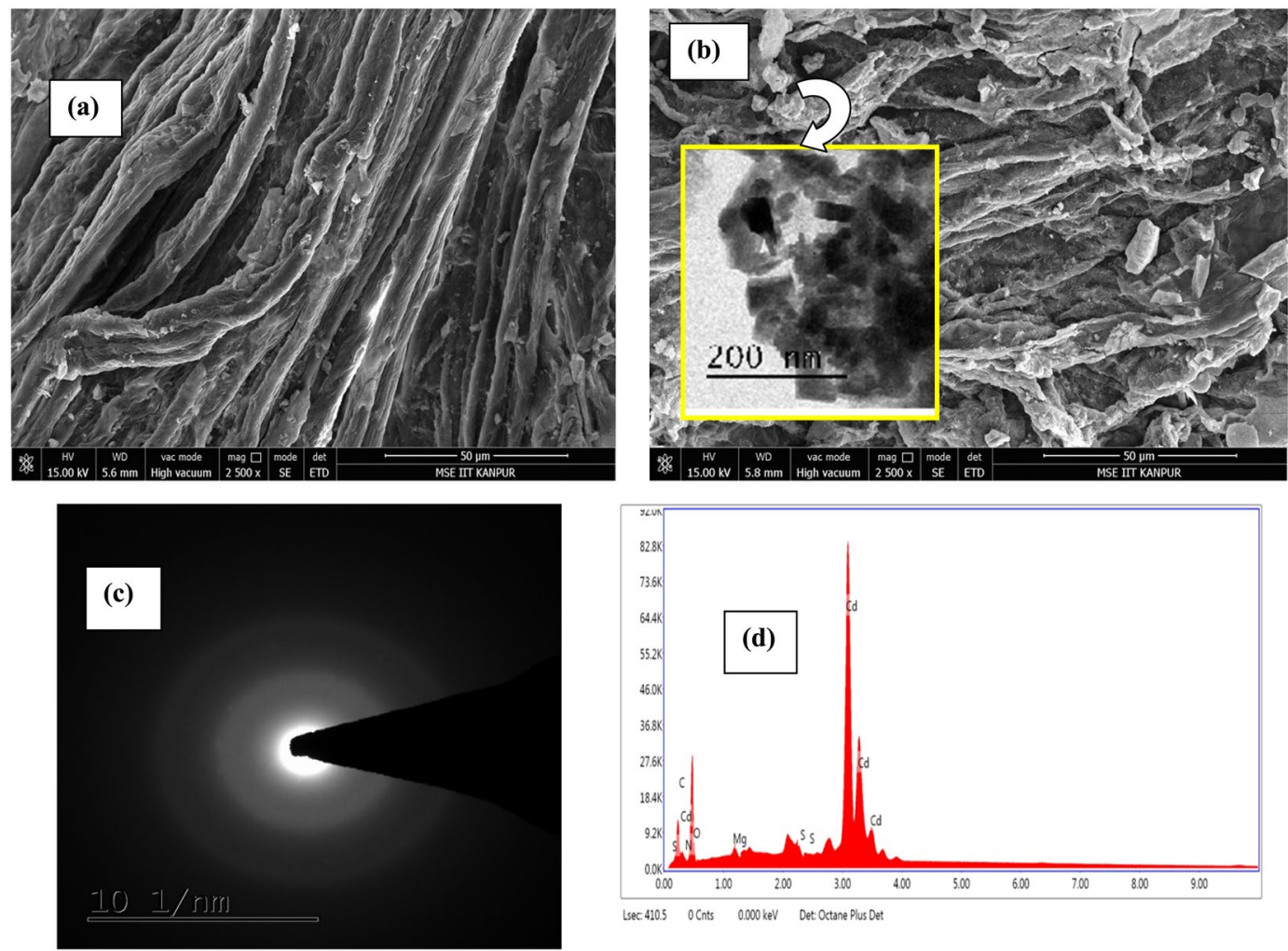

Figure 1. (a) SEM image of CNF (b). SEM image of Cd(II) loaded MgS@CNF inset TEM image of MgS (c). SAED pattern of MgS@CNF (d).EDAX plot of Cd-MgS@CNF.
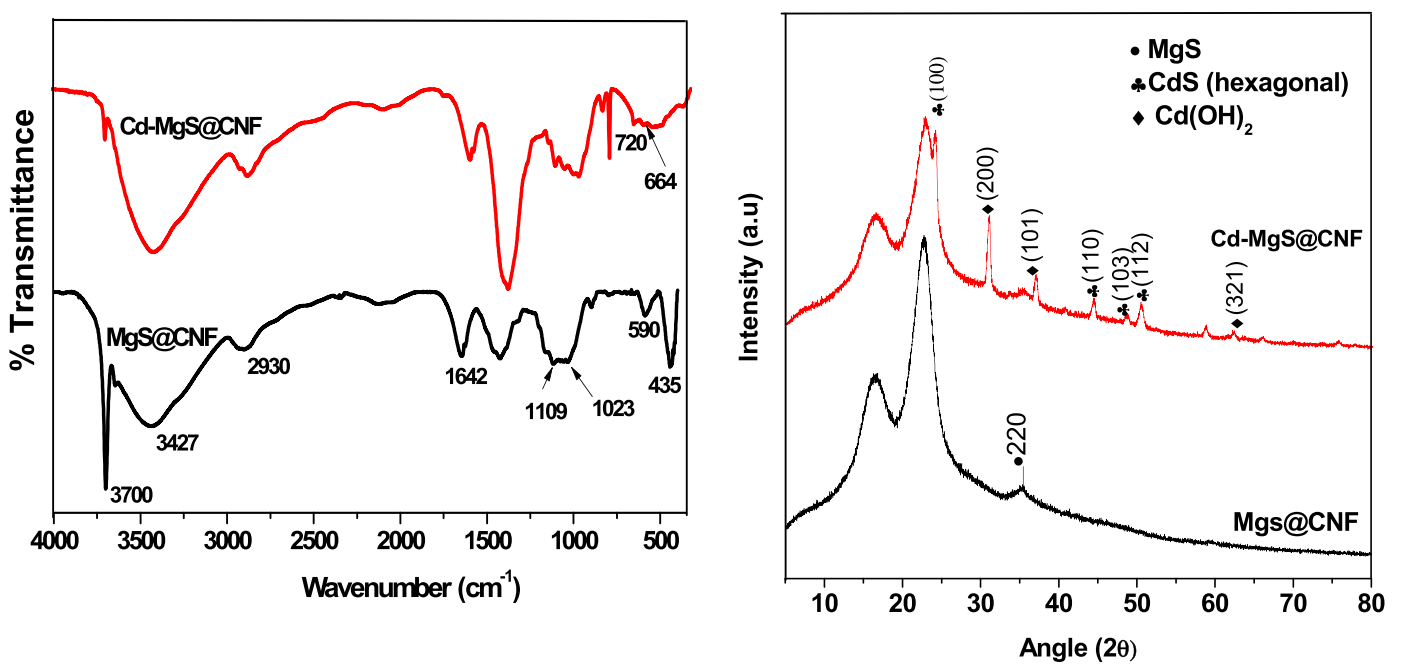

Figure 2. (a) FTIR spectra of MgS@CNF and Cd-MgS@CNF (b).XRD spectra of MgS@CNF and Cd-MgS@ CNF.

vibrations of hydrogen bonded cellulose moeity whereas the sharp peak around $3427 \mathrm{~cm}^{-1}$ is due to the free $-\mathrm{OH}$ stretching vibrations. The stretching bands of $\mathrm{O}-\mathrm{CH}_{3}$ are observed at $2930 \mathrm{~cm}^{-1}$ which arises from the trace lignin of cellulose fibres ${ }^{22,23}$. The S-O group gave rise symmetric and asymmetric vibrations at 1109 and $1023 \mathrm{~cm}^{-1}$ respectively ${ }^{24}$. Very sharp and strong bands are observed in both the spectra at $1642 \mathrm{~cm}^{-1}$ which could be attributed to non dissociated water molecules ${ }^{25}$. In MgS@CNF anchoring of sulfur molecules on cellulose nanofibers is proved by the presence of vibrations at $435 \mathrm{~cm}^{-1}$ and $590 \mathrm{~cm}^{-1}$ which is due to presence of polysulfide and disulfide respectively ${ }^{24}$. After Cd(II) adsorption, appearance of Cd-S stretching vibrations were observed at 664 and $720 \mathrm{~cm}^{-126}$ confirming the formation of CdS on the surface of MgS@CNF. The XRD pattern of MgS@CNF and Cd(II) loaded MgS@CNF were recorded and the diffraction pattern is shown in Fig. 2b. Sharp peaks were absent in MgS@CNF due to the amorphous nature of MgS. However, cadmium loaded MgS@CNF exhibited 

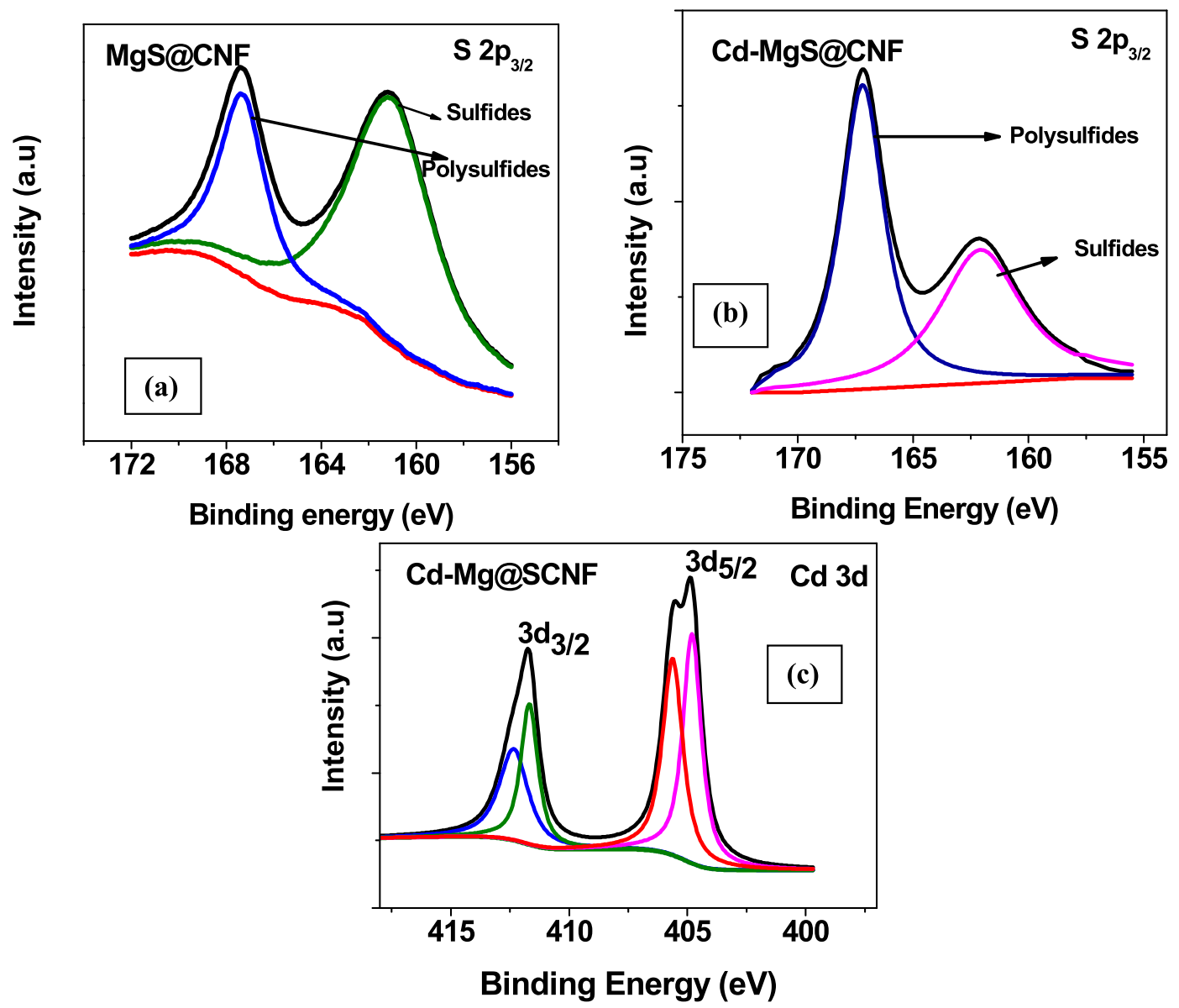

Figure 3. XPS molecular level spectra of S 2p in MgS@CNF (a). before and (b). after Cd(II) loading (c). Molecular level spectra of Cd 3d in Cd-MgS@CNF.

\begin{tabular}{|c|c|c|c|c|c|}
\hline $\begin{array}{l}\text { Before/After } \\
\text { Cd(II) Loading }\end{array}$ & Element & B.E. $(\mathrm{eV})$ & Fraction (\%) & Species & Reference \\
\hline Before & $\mathrm{Sp} 3 / 2$ & $\begin{array}{l}161.10 \\
167.31 \\
\end{array}$ & $\begin{array}{l}70.3 \\
29.7\end{array}$ & $\begin{array}{l}\mathrm{S}^{2-} \\
\text { Polysulfides of } \mathrm{Mg}\end{array}$ & 27,28 \\
\hline After & $\mathrm{Sp} 3 / 2$ & $\begin{array}{l}160.68 \\
166.00\end{array}$ & $\begin{array}{l}53.5 \\
46.5\end{array}$ & $\begin{array}{l}\text { CdS } \\
\text { Polysulfides of } \\
\text { Mg/Cd }\end{array}$ & 29,28 \\
\hline \multirow{2}{*}{ After } & $\mathrm{Cd} \mathrm{d} 5 / 2$ & $\begin{array}{l}412.3 \\
411.6\end{array}$ & $\begin{array}{l}19.8 \\
18.3\end{array}$ & $\begin{array}{l}\mathrm{CdS} \\
\mathrm{Cd}(\mathrm{OH})_{2}\end{array}$ & $30-33$ \\
\hline & $\mathrm{Cd} \mathrm{d} 1 / 2$ & $\begin{array}{l}405.6 \\
404.8\end{array}$ & $\begin{array}{l}31.9 \\
30.0\end{array}$ & $\begin{array}{l}\mathrm{CdS} \\
\mathrm{Cd}(\mathrm{OH})_{2}\end{array}$ & $30-33$ \\
\hline
\end{tabular}

Table 1. Molecular level XPS analysis of MgS@CNF before and after Cd(II) loading.

peaks indexed to $\mathrm{Cd}(\mathrm{OH})_{2}$ with strong (101), (200) and (321) reflections (JCPDS card No. 31-0118) and hexagonal CdS with strong reflections of miller indices (100), (110), (103) and (112) which are consistent with the literature values(JCPDS card No. 41-1049).

XPS survey spectra of cadmium loaded MgS@CNF exhibited peaks corresponding to sulfur, Mg and Cd indicating effective loading of magnesium and complexing of cadmium with sulfur ions (Fig. S1, Supporting Information). Furthermore the deconvoluted core level XPS spectra of S $2 p$ before and after loading with Cd are shown in Fig. 3a,b respectively. As expected, before Cd loading all the sulfur ions were either as monosulfides ${ }^{27}$ or polysulfides ${ }^{28}$ corresponding to binding energies 161.01 and $167.31 \mathrm{eV}$ respectively. However after Cadmium loading the binding energies of $S 2 p_{3 / 2}$ are shifted to lower binding energy values. The peak at binding energy value $160.68 \mathrm{ev}$ correspond to $\mathrm{CdS}^{29}$ and the strong peak at $166.0 \mathrm{ev}$ corresponds to polysulfides of $\mathrm{Cd} / \mathrm{Mg}$ ions. Figure (3c) depicts Cd-3d spectra, and the details are given in Table 1. It is evident that peaks were observed at $405.6 \mathrm{eV}$ and $412.3 \mathrm{eV}$ corresponding to $3 \mathrm{~d} 5 / 2$ and $3 \mathrm{~d} 3 / 2$ respectively. The binding energies obtained were consistent with that of $\mathrm{CdS}^{30,31}$ and in addition to these peaks, additional peaks of at $405.5 \mathrm{eV}$ for $3 \mathrm{~d} 5 / 2$ and $411.8 \mathrm{eV}$ for $3 \mathrm{~d} 3 / 2$ 

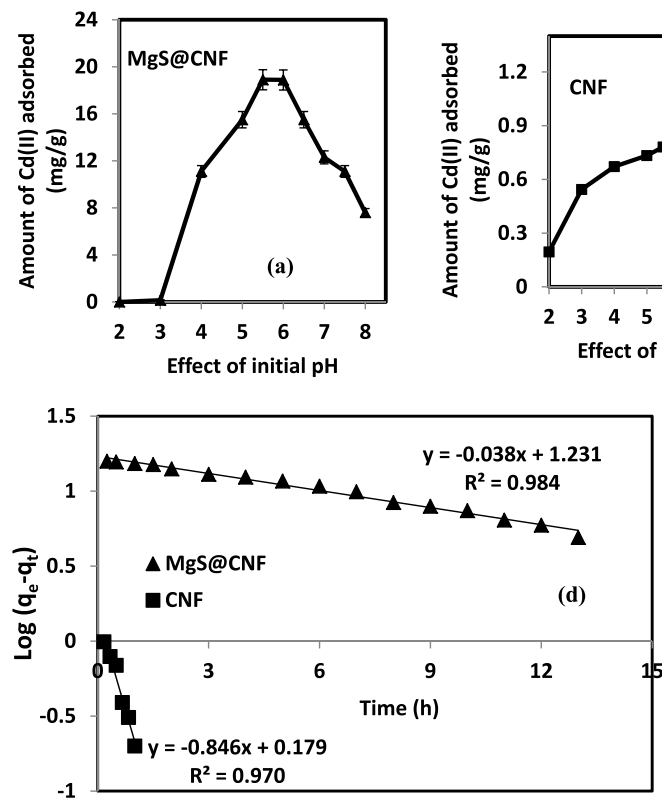

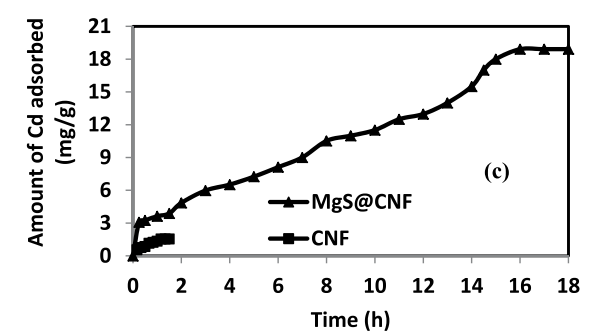

(b)

Effect of initial $\mathrm{pH}$
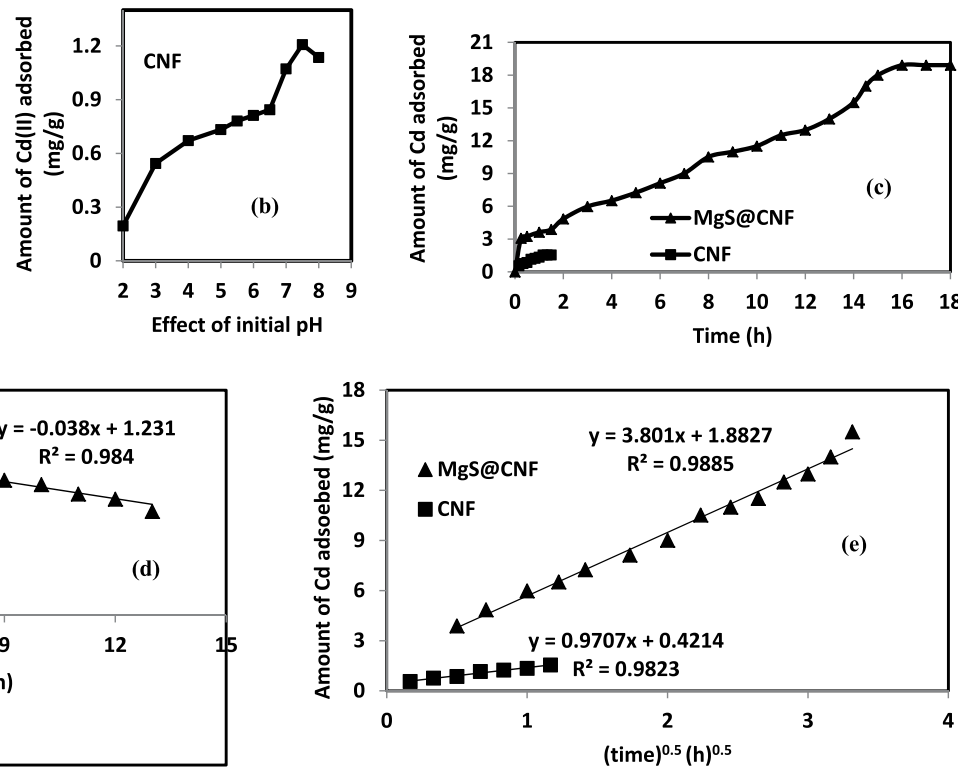

Figure 4. Effect of Initial pH on Cd(II) Adsorption by (a). MgS@CNF (b). CNF (c). Kinetics of Cd(II) Adsorption on CNF and MgS@CNF (d). Pseudo First order kinetics plot and (e). Web-morris plot of CNF and MgS@CNF and cadmium systems.

were obtained. These peak positions corresponds to cadmium hydroxide ${ }^{32,33}$. Thus from the afore mentioned discussions, following mechanism is postulated

$$
\begin{gathered}
2 \mathrm{MgS}+4 \mathrm{H}_{2} \mathrm{O}+2 \mathrm{H}^{+} \rightarrow 2 \mathrm{Mg}(\mathrm{OH})_{2}+2 \mathrm{H}_{2} \mathrm{~S} \\
2 \mathrm{MgS}_{2}+4 \mathrm{H}_{2} \mathrm{O}+4 \mathrm{H}^{+} \rightarrow 2 \mathrm{Mg}(\mathrm{OH})_{2}+4 \mathrm{H}_{2} \mathrm{~S} \\
\mathrm{Cd}(\mathrm{II})+\mathrm{H}_{2} \mathrm{~S} \rightarrow \mathrm{CdS}
\end{gathered}
$$

Apart from CdS, it is evident from XPS study that hydroxide salts of Cadmium are also observed which could be attributed to the interaction between the hydroxide groups of cellulose moiety with Cd(II) ions. Further, it is worth mentioning that EDX studies around 2.1 weight $\%$ of Sulfur is present on the adsorbent. Since we use low amount of adsorbent, the amount of hydrogen sulfide gas released is sufficient enough to remove the pollutant and will not pose a secondary pollution.

Effect of Initial pH on adsorption of Cd by MgS@CNF. Initial solution pH plays a significant role in the adsorption of Cd by MgS@CNF and CNF. There are two processes involved in the adsorption of Cd by MgS@ CNF. Initially, $\mathrm{MgS} / \mathrm{MgS}_{2}$ undergoes acid hydrolysis to yield insitu $\mathrm{H}_{2} \mathrm{~S}$ gas as depicted in equation 1 and 2. Later, produced $\mathrm{H}_{2} \mathrm{~S}$ gas reacts with $\mathrm{Cd}(\mathrm{II})$ ions to form $\mathrm{CdS}$ as shown in equation 3 . Thus at low $\mathrm{pH}$ though formation of $\mathrm{H}_{2} \mathrm{~S}$ is favorable it is ineffective in complexing with $\mathrm{Cd}$ ions. At very high $\mathrm{pH}$ values though formation of $\mathrm{CdS}$ is favorable, however, formation of $\mathrm{H}_{2} \mathrm{~S}$ is insignificant. Hence between $\mathrm{pH} 5.5$ to 6.0 both the processes namely evolution of $\mathrm{H}_{2} \mathrm{~S}$ and formation of $\mathrm{CdS}$ is favorable.

Thus from the Fig. 4a it is evident that adsorption is negligible at $\mathrm{pH}$ values less than 3 and then slowly it increases with increase in $\mathrm{pH}$. Cadmium removal increased from $77.5 \%$ to $94.5 \%$ with increase of $\mathrm{pH}$ from 5 to 5.5 and remained constant till pH 6 and further increase in $\mathrm{pH}$ to 8 resulted in decreased adsorption of around $40 \%$. In the case of CNF, it is evident that adsorption of $\mathrm{Cd}$ increases with $\mathrm{pH}$ and reaches a maximum of $10.72 \%$ at $\mathrm{pH} 7.5$ and subsequent increase in $\mathrm{pH}$ resulted in decreased adsorption of $\mathrm{Cd}$ ions by CNF. This could be attributed to the complexing of $\mathrm{OH}$ ions of cellulose and cadmium ions to form cadmium hydroxide. At higher $\mathrm{pH}$ values, cadmium exists as $\mathrm{Cd}(\mathrm{OH})_{2}$ and precipitation occurs and free $\mathrm{Cd}$ ions are unavailable for complexation.

Reaction kinetics of Cd with CNF and MgS@CNF. The reaction kinetics Cd removal by CNF and MgS@CNF indicated a rapid binding of Cd ions by the nanocomposite during the initial minutes followed by a gradual increase until a steady state of equilibrium was reached. Steady state was achieved after $1 \mathrm{~h}$ and $16 \mathrm{~h}$ of equilibration for CNF and MgS@CNF respectively (Fig. 4b). In the case of MgS@CNF slow release of $\mathrm{H}_{2} \mathrm{~S}$ took place and hence it took longer time to achieve equilibrium compared of plain CNF. Similar to this study longer equilibration times have been reported on the removal of $\mathrm{Cd}$ by $\operatorname{chitin}^{34}$, xanthated chitosan ${ }^{35}$. Obtained data was modeled by pseudo first order equation given below: 


\begin{tabular}{|c|c|c|c|c|c|c|c|c|c|c|c|}
\hline \multirow[b]{3}{*}{ Adsorbent $(\mathrm{pH})$} & \multicolumn{6}{|c|}{ Isotherm Constants } & \multicolumn{5}{|c|}{ Kinetics Constants } \\
\hline & \multicolumn{3}{|l|}{\begin{tabular}{|l|} 
Langmuir \\
\end{tabular}} & \multicolumn{3}{|c|}{ Freundlich } & \multicolumn{3}{|c|}{ Pseudo First Order } & \multicolumn{2}{|c|}{ Web Morris } \\
\hline & $\mathrm{Q}(\mathbf{m a x})(\mathrm{mg} / \mathrm{g})$ & b & $\mathbf{R}^{2}$ & $1 / n$ & $\mathbf{K}_{\mathrm{f}}$ & $\mathbf{R}^{2}$ & $k_{L}\left(\mathbf{h}^{-1}\right)$ & $q_{e}(\mathrm{mg} / \mathrm{g})$ & $\mathbf{R}^{2}$ & $\begin{array}{l}k_{\text {int }}(\mathrm{g} / \\
\left.\mathrm{mg} / \mathbf{h}^{0.5}\right)\end{array}$ & $\mathbf{R}^{2}$ \\
\hline CNF (7.5) & $7.81 \pm 0.56$ & 0.2415 & 0.99 & 3.559 & 2.576 & 0.911 & 0.0322 & 1.51 & 0.97 & 0.970 & 0.98 \\
\hline MgS@CNF (5.5) & $333.33 \pm 2.02$ & 0.1071 & 0.99 & 1.280 & 29.785 & 0.989 & 0.0875 & 17.02 & 0.98 & 3.801 & 0.99 \\
\hline
\end{tabular}

Table 2. Kinetic and isotherm parameters on adsorption of Cadmium by CNF and Mgs@CNF.
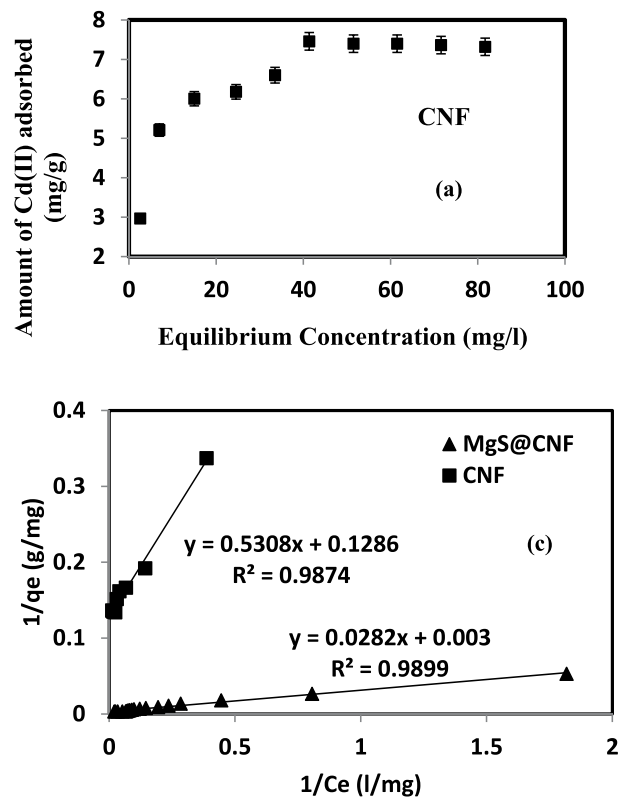
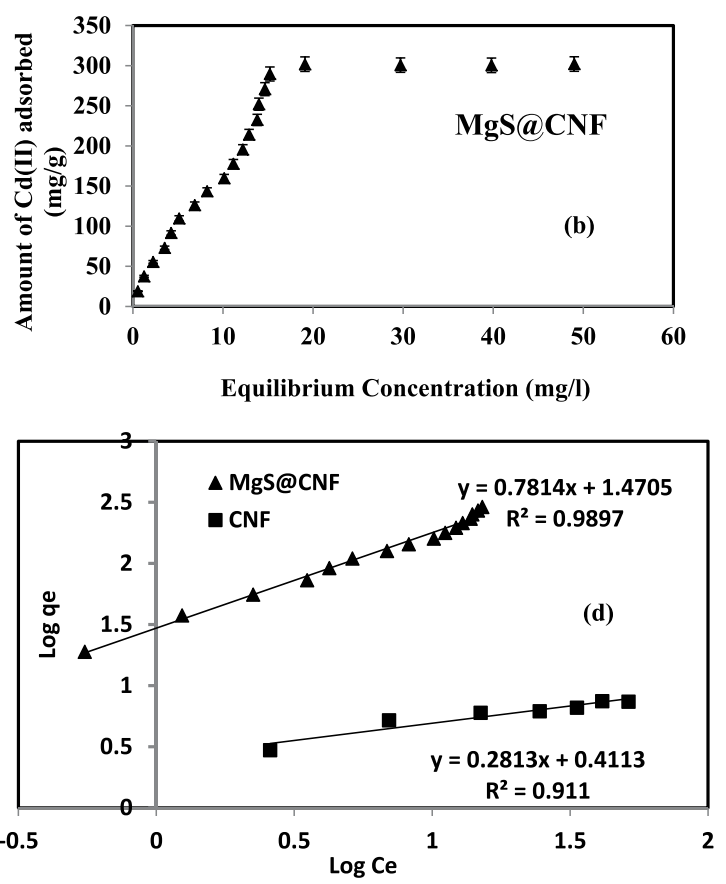

Figure 5. Equilibrium Adsorption isotherm (a) CNF (b). MgS@CNF, (c). Langmuir Plot and (d). Freundlich Plots of CNF and MgS@CNF and cadmium systems.

$$
\log \left(q_{e}-q_{t}\right)=\log \left(q_{e}\right)-\frac{k_{1}}{2.303} T
$$

where $\mathrm{q}_{\mathrm{e}}$ and $\mathrm{q}_{\mathrm{t}}$ are the amount of Cd ions adsorbed by MgS@CNF in $\mathrm{mg} / \mathrm{g}$ at given time " $\mathrm{T}$ ” and equilibrium respectively and $k_{1}$ is the pseudo first order constant in $\mathrm{h}^{-1}$. Various constants obtained are detailed in Table 2 and the plot is depicted in Fig. 4c. Adsorption of pollutants onto onto solid surface is also governed by intraparticle diffusion. Thus intraparticle diffusion rates of Cd ions onto CNF and MgS@CNF could be modeled using Weber and Morris model given by equation (5)

$$
q_{t}=K_{i n t} \sqrt{\mathrm{t}}
$$

where " $q_{t}$ " is the amount of Cd adsorbed by CNF/MgS@CNF at a given time " $\mathrm{t}$ " and " $K_{\text {int }}$ " is the intraparticle diffusion constant. Both CNF and MgS@CNF plots of qt $V s$ T yielded straight line with a high correlation coefficient and intercept Fig. (4d). Thus it could be concluded that the intraparticle diffusion of Cd ions onto CNF/MgS@ $\mathrm{CNF}$ is not the sole rate determining step governing sorption.

Adsorption isotherms of Cd with CNF and MgS@CNF systems. Cadmium adsorption equilibrium isotherms for CNF and MgS@CNF are shown in Fig. 5a. Obtained adsorption data using CNF and MgS@CNF were modeled using widely used Langmuir and Freundlich isotherm models. Unlike Freundlich model, Langmuir model is based on the assumption of monolayer and the both the models are represented by equations 6 and 7 respectively.

$$
\log q_{e}=\frac{1}{n} \log c_{e}+\log k_{f}
$$




\begin{tabular}{|c|c|c|c|c|c|c|c|c|c|c|c|c|}
\hline \multirow[b]{2}{*}{ Effluent } & \multicolumn{6}{|c|}{ Before Adsorption (mg/l) } & \multicolumn{6}{|c|}{ After Adsorption (mg/l) } \\
\hline & Cd & Total Cr & $\mathbf{P b}$ & Zn & As & COD & Cd & Total Cr & $\mathbf{P b}$ & $\mathrm{Zn}$ & As & COD \\
\hline 1 & 1.758 & 110.71 & 0.0015 & 0.0595 & 0.001 & 6857 & 0.003 & 12.521 & 0.0005 & 0.001 & 0.0005 & 3200 \\
\hline 2 & 2.516 & 121.91 & 0.0022 & 0.0785 & 0.002 & 6857 & 0.019 & 16.524 & 0.0007 & 0.002 & 0.0003 & 3550 \\
\hline 3 & 5.948 & 157.59 & 0.0031 & 0.0975 & 0.0014 & 20571 & 0.105 & 20.520 & 0.0006 & 0.003 & 0.0002 & 7360 \\
\hline
\end{tabular}

Table 3. Application of MgS@CNF to Industrial effluent.

$$
\frac{1}{q_{e}}=\frac{1}{c_{e} q_{\max b}}+\frac{1}{q_{\max }}
$$

where $\mathrm{q}_{\mathrm{e}}$ and $\mathrm{c}_{\mathrm{e}}$ are the amount of cadmium adsorbed $(\mathrm{mg} / \mathrm{g})$ and concentration of cadmium at equilibrium $(\mathrm{mg} / \mathrm{l})$ respectively. " $\mathrm{K}_{\mathrm{f}}$ " and " $\mathrm{n}$ " are freundlich adsorption and affinity constants. " $\mathrm{q}_{\max }$ " and "b" are Langmuir monolayer adsorption capacity $(\mathrm{mg} / \mathrm{g})$ and equilibrium constant $(\mathrm{ml} / \mathrm{mg})$ respectively. Langmuir and Freundlich plots are presented in Fig. 5b,c respectively and obtained adsorption constants are listed in Table 2. A comparison on the adsorption capacities of various sorbents recently reported in literature is listed in Table S1 of supporting information. Adsorbents anchored with sulfur containing groups are given for comparison purposes. It is evident from the data thatadsorption capacity of the MgS@CNF towards Cd(II) is higher than the ones reported in the literature. This could be attributed to the insitu generation of hydrogen sulfide gas which effectively complexes with Cd(II).

Thermodynamic studies. Thermodynamic parameters including change in Gibbs free energy $\left(\Delta \mathrm{G}^{\circ}\right)$, enthalpy $\left(\Delta \mathrm{H}^{\circ}\right)$ and entropy $\left(\Delta \mathrm{S}^{\circ}\right)$ were calculated by conducting the adsorption experiments of MgS@CNF and $\mathrm{Cd}(\mathrm{II})$ systems at three different temperatures namely 25,35 and $45^{\circ} \mathrm{C}$. From adsorption data, thermodynamic parameters were determined. Initially, $K c$, the equilibrium constant for MgS@CNF and Cd(II) was determined using equation (8)

$$
K_{C}=\frac{C_{A}}{C_{e}}
$$

where, $\mathrm{C}_{\mathrm{A}}(\mathrm{g} / \mathrm{L})$ is the concentration of $\mathrm{Cd}(\mathrm{II})$ in the aqueous phase and $\mathrm{C}_{\mathrm{e}}$ is the equilibrium concentration of $\mathrm{Cd}(\mathrm{II})(\mathrm{g} / \mathrm{l})$. Then, equation (9) was used calculate Gibbs free energy change change.

$$
\Delta G^{\circ}=-R T \ln K c
$$

where $\mathrm{R}$ is the gas constant, T is the temperature in Kelvin. Further, Van't Hoff equation (10) was used to calculate entropy $(\Delta S)$ and enthalpy change $(\Delta \mathrm{H})$ was determined:

$$
\log K c=\frac{\Delta S^{\circ}}{2.303}-\frac{\Delta H^{\circ}}{2.303 R T}
$$

A linear plot was constructed between $\ln K_{c}$ vs. $1 / \mathrm{T}$ of $\mathrm{Cd}(\mathrm{II})$ and $\mathrm{MgS} @ \mathrm{CNF}$, and $\Delta \mathrm{S}^{\circ}$ and $\Delta \mathrm{H}^{\circ}$ were determined from the intercept and slope, respectively. The results obtained are presented in Table S2 of the supporting information. The spontaneity and feasibility of the adsorption process between MgS@CNF and Cd(II) ions is indicated by negative free energy values, while the positive $\Delta \mathrm{H}^{\circ}$ values indicate the endothermic nature of the sorption process. Entropy $\left(\Delta S^{\circ}\right)$ of adsorption yielded positive values which could be attributed to Cd(II) ion dehydration during surface sorption onto MgS@CNF.

Application to real industrial effluent. Industrial effluent from local tanneries was collected and the characteristics of the same are listed in Table S2 of the supporting information. Tannery effluents were treated with $0.1 \mathrm{~g}$ of MgS@CNF after 10 times dilution and adjusting the pH 5.5. The solutions were equilibrated for 16h and the concentration of cadmium and other heavy metal ions were determined by ICPMS. It is evident from the data (Table 3) that MgS@CNF is effective in removing the cadmium concentration from ppm to ppb levels. Apart from cadmium, it is also evident that it is efficient in bringing down the concentration other metal ions including $\mathrm{Cr}, \mathrm{Pb}, \mathrm{As}, \mathrm{Zn}$ and $\mathrm{COD}$ as well. Insitu generation of $\mathrm{H}_{2} \mathrm{~S}$ during adsorption promotes the precipitation of other soft metals like $\mathrm{Zn}, \mathrm{Pb}$, As and $\mathrm{Zn}$ onto the surface of the adsorbent and thus we observe the reduction in concentration of these metal ions. Tannery effluent comprises both $\mathrm{Cr}(\mathrm{VI})$ and $\mathrm{Cr}(\mathrm{III})$ species. During adsorption, $\mathrm{Cr}(\mathrm{VI})$ could be reduced to $\mathrm{Cr}$ (III) by the sulfide ions. Reduced $\mathrm{Cr}$ (III) and $\mathrm{Cr}$ (III) already present in tannery effluent could be immobilized as hydroxides/sulfides onto the adsorbent surface. Because of this redox reaction a decreased value of chemical oxygen demand is observed after adsorption. Hence the prepared adsorbent could be applicable to treat other wastewaters as well.

\section{Materials and Methods}

Materials required. Various chemicals including, sodium/Potassium hydroxide $(\mathrm{NaOH} / \mathrm{KOH})$, bleach $(\mathrm{NaOCl})$, nitric acid $\left(\mathrm{HNO}_{3}\right)$, Sodium Sulfide $\left(\mathrm{Na}_{2} \mathrm{~S}\right)$, Magnesium sulfate $\left(\mathrm{MgSO}_{4}\right)$, hydrochloric acid $(\mathrm{HCl})$, Cadmium nitrate $\left(\mathrm{Cd}\left(\mathrm{NO}_{3}\right)_{2} \cdot 4 \mathrm{H}_{2} \mathrm{O}\right)$ and other reagents used were of $\mathrm{AR}$ grade. All the reagents and standards were prepared with Milli-Q water with a resistivity $>18.2 \mathrm{M} \Omega \mathrm{cm}$. 
Preparation of MgS@CNF. Agrowaste namely dried and powdered sugarcane bagasse was used to prepare cellulose nanofibers by the procedure reported elsewhere ${ }^{23}$. Briefly soxhlet extraction was initially performed on raw sugarcane bagasse for $6 \mathrm{~h}$ using organic mixture consisting of toluene and ethanol to remove the organic contaminants. Further, degradation of lignin was carried out using combination of bleach and acetic acid. Washing the product with distilled water and further treatment with $\mathrm{KOH}$ resulted in the removal of hemicelluloses moiety. This was followed by acid wash to remove residual alkali and air dried to obtain cellulose nanofibers (CNF).

Initially $2 \mathrm{~g}$ CNF was placed in a two neck Erlenmeyer flask with $200 \mathrm{~mL}$ of Milli Q water. This was followed by addition of $40 \mathrm{ml} 0.2 \mathrm{M} \mathrm{MgSO}_{4} \cdot 7 \mathrm{H}_{2} \mathrm{O}$ and the resultant mixture was stirred for $15 \mathrm{~min}$. Further, around $20 \mathrm{ml}$ of $0.4 \mathrm{M} \mathrm{Na}_{2} \mathrm{~S}$ was added gradually using a syringe. The whole setup was kept in nitrogen atmosphere to avoid air oxidation. Continuous stirring for $30 \mathrm{~min}$. ensured successful completion of the reaction and obtained product was washed and further heated for $200^{\circ} \mathrm{C}$ in inert $\left(\mathrm{N}_{2}\right)$ atmosphere for $2 \mathrm{~h}$ to obtain MgS@CNF. Obtained MgS@ $\mathrm{CNF}$ was stored in dessicator until further use.

Characterization of MgS@CNF. FEI Quanta 200 microscope was used for Energy Dispersive X-ray (EDX) and Field emission scanning electron microscopy (FE-SEM) images and after gold coating. Fourier Transform Infra-red (FTIR) spectra of Virgin and cadmium loaded MgS@CNF was obtained using Tensor 27 (Bruker, Germany). X-ray photoelectron spectroscopic measurements (XPS) were recorded with PHI 5000 Versa ProbII, FEI Inc. using a monochromatic $\mathrm{Al} \mathrm{K \alpha}$ radiation $(1486.6 \mathrm{eV})$. Deconvoluted spectra of Cd and Sulfur were produced using XPS PEAK 4.1 software with a Gaussian-Lorentzian sum function.

Equilibrium adsorption experiments with CNF and MgS@CNF. Equilibrium adsorption experiments with both CNF and MgS@CNF in batch reactors. Equilibrations with both nanomaterials were performed for $16 \mathrm{~h}$, maintaining the temperature at $25^{\circ} \mathrm{C}$ in shaking incubator set to an rpm of 110 . Filtration of samples were carried out after equilibration and analyzed for $\mathrm{Cd}(\mathrm{II})$ after suitable dilutions using inductively coupled plasma mass spectrometer (ICPMS). The experimental conditions performed were: dose of adsorbent: $0.5 \mathrm{~g} / \mathrm{l}$, pH: 5.5 for MgS@CNF and pH: 7.5 for CNF, equilibration time: $16 \mathrm{~h}$, initial concentration of Cd(II): $10 \mathrm{mg} / \mathrm{l}$, total aqueous volume: $20 \mathrm{ml}$. Equilibrium isotherm experiments were performed by varying initial Cd(II) concentrations (10 to $200 \mathrm{mg} / \mathrm{l}$ ) for MgS@CNF and 10 to $100 \mathrm{mg} / \mathrm{l}$ for CNF. The amount of Cd(II) adsorbed by CNF and MgS@CNF were obtained from eqn (11):

$$
q_{e}=\frac{\left(C_{i}-C_{e}\right) X V}{W}
$$

where $q_{e}$ is the quantity of $\mathrm{Cd}(\mathrm{II})$ adsorbed by both the prepared adsorbents $(\mathrm{mg} / 1), C_{i}$ and $C_{e}$ are the initial and equilibrium Cd(II) concentration (mg/1), W is the mass of the sorbent used $(\mathrm{g}) \mathrm{V}$ is final aqueous volume. For kinetic studies, determination of Cd(II) uptake was carried at defined time intervals.

\section{Conclusions}

In the present study $\mathrm{MgS}$ doped cellulose nanofibres were prepared characterized and applied towards the removal of Cadmium from industrial wastewater. Cellulose nanofibers acted as a template for the effective dispersion of MgS. MgS acted as source of sulfide ions for complexing cadmium. The Langmuir monolayer adsorption capacity towards Cd(II) for MgS@CNF (333.3 mg/g) was found to be higher than virgin CNF (7.81 mg/g). Effective anchoring of MgS was evident from XPS and XRD studies. Detailed spectroscopic investigations revealed the formation of $\mathrm{CdS}$ which accounts for the very high adsorption capacity. Furthermore, the ability of MgS@CNF to remove Cd ions from industrial waste water is demonstrated. Finally, it could be postulated that similar to $\mathrm{Cd}$, prepared adsorbent can find application in the removal of other heavy metal ions like $\mathrm{Cr}(\mathrm{VI})$, $\mathrm{Hg}(\mathrm{II}), \mathrm{Pb}(\mathrm{II}), \mathrm{Cu}(\mathrm{II})$ as well.

\section{References}

1. Kumar, R., Chawla, J. \& Kaur, I. Removal of cadmium ion from wastewater by carbon-based nanosorbents: a review. Journal of Water and Health. 13(1), 18-33 (2015).

2. Purkayastha, D., Mishra, U. \& Biswas, S. A comprehensive review on Cd(II) removal from aqueous solution. Journal of Water Process Engineering. 2, 105-128 (2014).

3. Wang, K., Tao, X., Xu, J. \& Yin, N. Novel chitosan-MOF composite adsorbent for the removal of heavy metal ions. Chemistry letters. 45, 1365-1368 (2016).

4. Dhanarani, S., Viswanathan, E., Piruthiviraj, P., Arivalagan, P. \& Kaliannan, T. Comparative study on the biosorption of aluminum by free and immobilized cells of Bacillus safensis KTSMBNL 26 isolated from explosive contaminated soil. Journal of the Taiwan Institute of Chemical Engineers. 000, 1-7 (2016).

5. Sud, D., Mahajan, G. \& Kaur, M. P. Agricultural waste material as potential adsorbent for sequestering heavy metal ions from aqueous solutions-A review. Bioresource technology. 99(14), 6017-6027 (2008).

6. Lo, S. F., Wang, S. Y., Tsai, M. J. \& Lin, L. D. Adsorption capacity and removal efficiency of heavy metal ions by Moso and Ma bamboo activated carbons. Chemical Engineering Research \& Design. 90(9), 1397-1406 (2012).

7. Eeshwarasinghe, D., Loganathan, P. \& Vigneswaran, S. Simultaneous removal of polycyclic aromatic hydrocarbons and heavy metals from water using granular activated carbon. Chemosphere. 223, 616-627 (2019).

8. Ugrina, M., Medvidovic, N. V., Trgo, M. \& Nuic, I. Optimization of removal efficiency and minimum contact time for cadmium and zinc removal onto iron-modified zeolite in a two-stage batch sorption reactor. Chemical and Biochemical Engineering Quarterly. 31(4), 425-435 (2018).

9. Soto Hidalgo, K. T. et al. Photoelectrochemical Solar Cells Prepared From NanoscaleZerovalent Iron Used for Aqueous Cd2+ Removal. ACS Sustainable Chemistry and Engineering. 4, 738-745 (2016).

10. Guo, X. et al. Simple combination of oxidants with zero-alent-iron (ZVI) achieved very rapid and highly efficient removal of heavy metals from water. Water Research. 88, 671-680 (2016).

11. Sankararamakrishnan, N., Jaiswal, M. \& Verma, N. Composite nanofloral clusters of carbon nanotubes and activated alumina: An efficient sorbent for heavy metal removal. Chemical Engineering Journal. 235, 1-9 (2014). 
12. Oyetade, O. A., Nyamori, V. O., Jonnalagadda, S. B. \& Martincigh, B. S. Removal of $\mathrm{Cd} 2+$ and $\mathrm{Hg} 2+$ from aqueous solutions by adsorption onto nitrogen-functionalized carbon nanotubes. Desalination and Water Treatment. 108, 253-267 (2018).

13. Mudila, H. et al. An insight into Cadmium poisoning and its removal from aqueous sources by Graphene Adsorbents. International Journal of Environmental Health Research. 29(1), 1-21 (2019).

14. Pal, P. \& Pal, A. Modifications of chitosan for cadmium removal: A short review. Journal of Polymer Materials. 34(1), 331-341 (2017).

15. Chauhan, D., Jaiswal, M. \& Sankararamakrishnan, N. Removal of cadmium and hexavalent chromium from electroplating waste water using thiocarbamoyl chitosan. Carbohydrate Polymers. 88(2), 670-675 (2012).

16. Dai, Y., Sun, Q., Wang, W., Gao, F. \& Zhang, Y. Utilizations of agricultural waste as adsorbent for the removal of contaminants. A review: Chemosphere. 211, 235-253 (2018).

17. Pyrzynska, K. Removal of cadmium from wastewaters with low cost adsorbents. Journal of Environmental Chemical Engineering 102795 (2019).

18. Shang, Z., Zhang, L., Zhao, X., Liu, S. \& Li, D. Removal of $\mathrm{Pb}(\mathrm{II}), \mathrm{Cd}(\mathrm{II})$ and $\mathrm{Hg}(\mathrm{II})$ from aqueous solution by mercapto-modified coal gangue. Journal of Environmental Management. 231, 391-396 (2019).

19. Venkateswarlu, S. \& Yoon, M. Rapid removal of cadmium ions using green-synthesized Fe3 O4 nanoparticles capped with diethyl-4-(4 amino-5-mercapto-4H-1,2,4-triazol-3-yl)phenyl phosphonate. RSC Advances. 5(80), 65444-65453 (2015).

20. Gong, J. et al. Adsorption of heavy metal ions by hierarchically structured magnetite-carbonaceous spheres. Talanta. 101, 45-52 (2012).

21. Gupta, A., Vidyarthi, S. R. \& Sankararamakrishnan, N. Enhanced sorption of mercury from compact fluorescent bulbs and contaminated water streams using functionalized multiwalled carbon nanotubes. Journal of Hazardous Materials. 274, 132-144 (2014).

22. Nada, A. A. M. A., El-Sakhawy, M. \& Kamel, S. M. Infra-red spectroscopic study of lignins. Polymer degradation and stability. 60, 247-251 (1998).

23. Sankararamakrishan, N., Shankwar, A. K. \& Chauhan, D. Mechanistic insights on immobilization and decontamination of hexavalent chromium onto nanoMgS/FeS doped cellulose nanofibres. Chemosphere. 228, 390-397 (2019).

24. Mikhlin, Y. et al. Reactivity of Pyrrhotite (Fe9S10) Surfaces: Spectroscopic Studies. Physical chemistry chemical physics. 2, 4393-4398 (2000).

25. Babou, F., Coudurier, G. \& Vedrine, J. C. Acidic properties of sulfated zirconia: An infrared spectroscopic study. Journal of Catalysis. 152, 341-349 (1995).

26. Devi, R., Purkayastha, P., Kalita, P. K. \& Sharma, B. K. Synthesis of nanocrystallineCdS thin films in PVA matrix. Bulletin of Materials Science. 30, 123 (2007).

27. Pratt, A. R., Muir, I. J. \& Nesbitt, H. W. X-ray photoelectron and Auger electron studies of pyrrhotiteand mechanism of air oxidation. GeochimicaetCosmochimicaActa. 8, 5147-5159 (1994).

28. Kim, H. S. et al. Structure and compatibility of a magnesium electrolyte with a sulphur cathode.Nature. Communications 2,427 (2011).

29. Kolhe, S., Kuljarni, S. K., Nigavekar, A. S. \& Sharma, S. K. Effects of air annealing on chemically deposited CdS films examined by XPS and XRD. Solar Energy materials. 10, 47-54 (1984).

30. Gaarenstroom, S. W. \& Winograd, N. J. Journal of Chemical Physics 67, 3500 (1977).

31. Bhide, V. G., Salkalachen, S., Rastog, A.C. C., Rao, N. R. \& Hegde, M. S. Journal of Physics D: Applied Physics. 14, 1647 (1981).

32. Hammond, J. S., Gaarenstroom, S. W. \& Winograd, N. X-Ray Photoelectron Spectroscopic Studies of Cadmium- and Silver-Oxygen Surfaces. Analytical Chemistry. 47, 2194 (1975).

33. Wagner, C. D., Riggs, W. M., Davis, L. E., Moulder, J. F. \& Muilenberg, G. E. Handbook X-Ray Photoelectron Spectroscopy. Ed PerkinElmer, (1979).

34. Benguella, B. \& Benaissa, H. Cadmium removal from aqueous solutions by chitin: Kinetic equilibrium studies. Water research. 36, 2463-2474 (2002).

35. Sankararamakrishnan, N., Sharma, A. K. \& Sanghi, R. Novel chitosan derivative for the removal of cadmium in the presence of cyanide from electroplating wastewater. Journal of Hazardous Materials. 148(1-2), 353-359 (2007).

\section{Acknowledgements}

The authors would like to thank Department of Science and Technology (DST), New Delhi, India (ref No. SR/WOS-A/CS-10/2016) for the research funding. The fellowship for NS by DST is gratefully acknowledged. Advanced centre for material sciences, Advanced Imaging Centre and Thematic Unit of Excellence on Soft Nanofabrication, at IIT Kanpur are acknowledged for various characterization studies.

\section{Author Contributions}

N.S. and R.S. designed and conceived the experiment. R.S. and I.S. carried out the experiment. N.S. wrote the manuscript. All the authors took part in the discussion throughout the study.

\section{Additional Information}

Supplementary information accompanies this paper at https://doi.org/10.1038/s41598-019-49076-2.

Competing Interests: The authors declare no competing interests.

Publisher's note: Springer Nature remains neutral with regard to jurisdictional claims in published maps and institutional affiliations.

(c) (i) Open Access This article is licensed under a Creative Commons Attribution 4.0 International

License, which permits use, sharing, adaptation, distribution and reproduction in any medium or format, as long as you give appropriate credit to the original author(s) and the source, provide a link to the Creative Commons license, and indicate if changes were made. The images or other third party material in this article are included in the article's Creative Commons license, unless indicated otherwise in a credit line to the material. If material is not included in the article's Creative Commons license and your intended use is not permitted by statutory regulation or exceeds the permitted use, you will need to obtain permission directly from the copyright holder. To view a copy of this license, visit http://creativecommons.org/licenses/by/4.0/.

(C) The Author(s) 2019 